\title{
The Sludge Dewaterability in Advanced Wastewater Treatment: A Survey of Four Different Membrane BioReactor Pilot Plants
}

\author{
G. Mannina ${ }^{(\bowtie)}$, M. Capodici, and G. Viviani \\ Dipartimento di Ingegneria Civile, Ambientale, Aerospaziale, \\ dei Materiali, Università degli Studi di Palermo, Palermo, Italy
}

\begin{abstract}
The wasted activated sludge dewaterability represents a major concern for Wastewater Treatment Plants (WWTPs) managers. Indeed, whereas the dewatered sludge could represents a re-usable matrix, the principal drawback related to the wasted sludge dewaterability is the high water content due to the presence of extracellular polymeric substances (EPS) that allow the trapping of water molecules within the bio sludge flocs. In order to provide an outlook of the dewaterability features of activated sludge derived from advanced WWTP, the present research reports a long term survey (over two years) aimed at assessing the principal dewaterability parameters of the sludge wasted from different Membrane BioReactor pilot plants.
\end{abstract}

Keywords: Sludge dewaterability $\cdot \mathrm{MBR} \cdot \mathrm{EPS} \cdot \mathrm{CST} \cdot \mathrm{SRF}$

\section{Introduction}

The wasted activated sludge dewaterability represents a major concern for Wastewater Treatment Plants (WWTPs) managers. Indeed, whereas the dewatered sludge could represents a re-usable matrix (e.g., as a supplement to composting or as a feedstock to energy production, Skinner et al. 2015), the re-use results limited by the high cost involved in transport and drying.

Furthermore, when sludge features avoid the re-use, the disposal costs significantly affect the WWTP economical management, up to 60\% (Chen et al. 2016; Low et al. 2000). As the cost for sludge treatment and disposal ranges around 280-470 €/t and since $1 \mathrm{t}$ of fresh sludge to be disposed is composed on average by $0.25-0.30 \mathrm{t}$ of suspended solids (SS), the correct understanding of dewaterability phenomenon represents a key factor in order to improve the effectiveness of water separation process (Capodici et al. 2016; Ginestet 2007).

In order to cope with the needing of reduce sludge impact on the economic management of WWTP, researcher and designer interest moved in developing and refining treatment technologies such as membrane bioreactors (MBR), capable to reduce the specific sludge production. However, despite such efforts mechanical dewatering represents up to nowadays a crucial step in reducing the amount of sludge to be disposed (Marinetti et al. 2009). 
Several studies have been carried out in order to identify the most effective dewatering strategy (among others, Bonilla et al. 2015; Chen et al. 2016; Liu et al. 2016; Rao et al. 2017). The principal drawback related to the wasted sludge dewaterability is the high water content due to the presence of extracellular polymeric substances (EPS) that allow the trapping of water molecules within the bio sludge flocs (Mowla et al. 2013).

In details, four different types of water contained in sludge have been defined: free water, interstitial water, vicinal water and water of hydratation.

More in details, gravitational settling can easily separate free water. Mechanical dewatering devices, such as centrifugation or vacuum filtration, can achieve interstitial water separation. Any mechanical device cannot separate vicinal water, physically bound to solid particles surface. Water of hydratation, chemically bound to solid particles surface, can be separated only by heating at temperature above $105^{\circ} \mathrm{C}$ (Mowla et al. 2013).

However, it is worth noticing that also the WWTP layout, affecting the metabolic reactions that may occur, play a role in the complex dewaterability phenomenon. Indeed, the sludge origin is recognized as one of the key factor involved in sludge dewaterability (Capodici et al. 2016; Jin et al. 2004; Wang et al. 2014).

In order to provide an outlook of the dewaterability features of activated sludge derived from advanced WWTP, the present research reports a long term survey (over two years) during which the principal dewaterability parameters of the wasted sludge were investigated.

In details, four different WWTPs layout were investigated: System batch reactor (SBR), pre denitrification scheme, University of Cape Town (UCT) scheme and Integrated Fixed Film Activated Sludge (IFAS) operated in UCT scheme.

Furthermore, it was applied also a variation of the influent wastewater features and the operational parameters, such as sludge retention time (SRT) and hydraulic retention time (HRT). During the aforementioned layout the solid liquid separation was achieved by means of an hollow fibres ultrafiltration (UF) unit, thus applying the Membrane Bio Reactor (MBR) technology.

\section{Materials and Methods}

The sludge investigated in the present study were collected from 4 different MBR pilot plant, realized at the Laboratory of Sanitary and Environmental Engineering of Palermo University, fed with wastewater taken from the sewer system of the Palermo University and operated in 7 different conditions (see Table 1).

During the configuration I, II and III, solid-liquid separation was performed via UF membrane module Zenon Zeeweed, ZW 10, with specific area equal to $0.98 \mathrm{~m}^{2}$ and a nominal porosity of $0.04 \mu \mathrm{m}$. During configurations IV, V, VI, and VII the solid-liquid separation phase was carried out by means of an UF module Koch PURON® 3 bundle with specific area equal to $1.40 \mathrm{~m}^{2}$ and a nominal porosity of $0.03 \mu \mathrm{m}$.

The dewaterability was investigated by measuring, in accordance with literature (Capodici et al. 2016), in mixed liquor samples collected from each biological reactor, the Capillary Suction Time (CST) and the Specific Resistance to Filtration (SRF) in void conditions $(-50 \mathrm{kPa})$. 
Table 1. Layout and operative condition of the investigated MBR systems

\begin{tabular}{l|l|l|l|l}
\hline Phase & WWTP Layout & $\begin{array}{l}\text { MBR } \\
\text { module }\end{array}$ & Operative condition & Reference \\
\hline I & SBR-DN-MBR & ZW10 & $\begin{array}{l}\text { Stepwise salinity (0-10 } \\
\text { gNaCl L } ~^{-1} \text { ) }\end{array}$ & $\begin{array}{l}\text { (Mannina et al. } \\
\text { 2016a) }\end{array}$ \\
\hline II & DN-MBR & ZW10 & $\begin{array}{l}\text { Stepwise salinity (10-20 } \\
\mathrm{gNaCl} \mathrm{L}^{-1} \text { ) }\end{array}$ & $\begin{array}{l}\text { (Mannina et al. } \\
\text { 2016b) }\end{array}$ \\
\hline III & DN-MBR & ZW10 & $\begin{array}{l}20 \mathrm{gNaCl} \mathrm{L}^{-1} \text { and diesel } \\
\text { fuel }\end{array}$ & $\begin{array}{l}\text { (Mannina et al. } \\
\text { 2016b) }\end{array}$ \\
\hline IV & UCT-MBR & PURON & Influent C/N variation & $\begin{array}{l}\text { (Mannina et al. } \\
\text { 2016c) }\end{array}$ \\
\hline V & UCT-IFAS-MBR & PURON & SRT variation & \\
\hline VI & UCT-IFAS-MBR & PURON & Influent C/N variation & \\
\hline VII & UCT-IFAS-MBR & PURON & HRT/SRT variation & \\
\hline
\end{tabular}

Furthermore, in order to highlight the influence exerted by the biological behaviour of biomass on the dewaterability features, the main chemical parameters were measured in accordance with standard methods (APHA 2005): among others, Chemical Oxygen Demand (COD), Total Nitrogen (TN), and nitrogen forms (NH4-N, NO2-N, NO3-N), Total Suspended Solid (TSS). Moreover, since the EPS content of mixed liquor is recognized as a key factor related to sludge dewaterability features, the total EPS content and the Soluble Microbial Product (SMP) were measured in accordance with literature (Capodici et al. 2014; Cosenza et al. 2013).

\section{Results}

A correspondence between the sludge dewaterability features and the different lay out configurations was noticed.

In Fig. 1, the mean values of CST measured in the aerobic reactor during each experimental Phase are depicted.

Reported data allow to observe that during the Phases I, II and III (salinity stepwise phase and diesel fuel addition, see Table 1), the CST increased with the salinity increase. Thus, when diesel fuel was treated, the CST (as well as SRF) sharply increased (142 $\mathrm{s}$ as maximum CST measured during Phase III).

The SRF measurements provided similar results, thus corroborating the CST findings with respect to the progressive decrease of sludge filterability during Phase III. The worsening in the sludge filterability was also noticed by filtering the sample collected for the chemical analysis. Indeed, a longer duration of the vacuum pump operations needed to collect significant volumes of filtered sample was required during Phase III.

Furthermore, after filtration, the filtration media resulted covered by a homogeneous jelly layer. Such result is likely ascribable to a progressive increase in sludge viscosity due both to the salinity increase and to the hydrocarbon presence. 


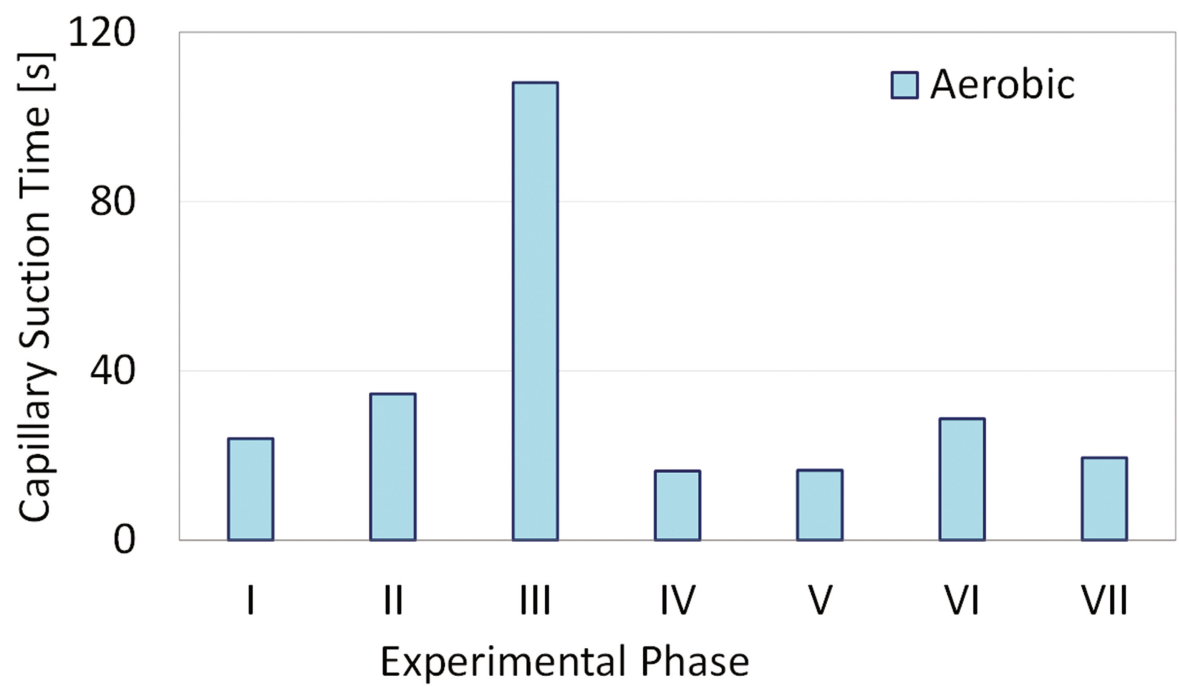

Fig. 1. Mean values of Capillary Suction Time measured on sludge collected from aerobic reactor during the experimentation

Furthermore, during the experimentation it was noticed the influence exerted by EPS and SMP content. In Fig. 2 some correlations involving EPS, SMP, CST and SRF during Phase $\mathrm{V}$ are depicted.

a)

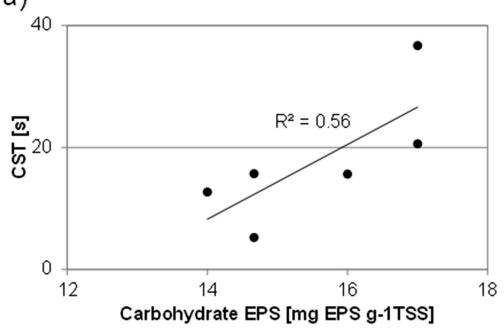

c)

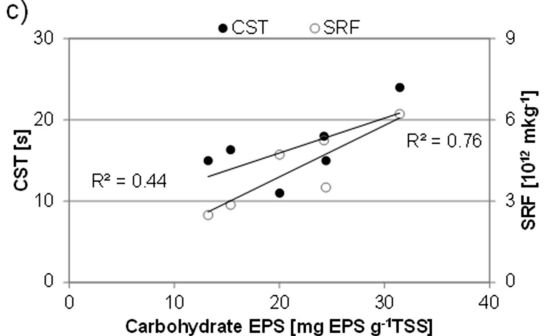

b)

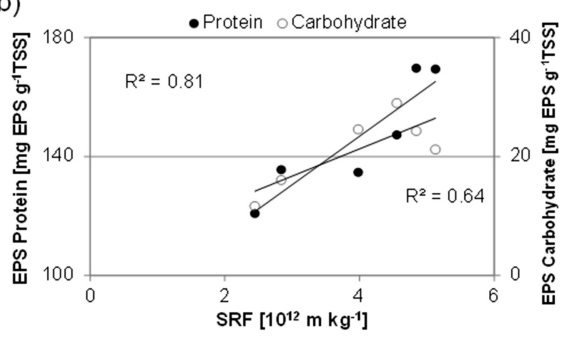

d)

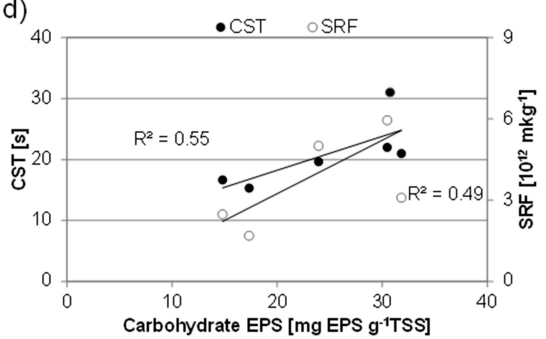

Fig. 2. Correlation during Phase V: CST vs specific bound carbohydrates EPS in anaerobic reactor (a); specific bound proteins and carbohydrates EPS vs SRF in anoxic reactor(b); CST and SRF vs specific bound carbohydrates EPS in aerobic reactor (c); CST and SRF vs specific bound carbohydrates EPS in MBR reactor (d) 
Results reported in Fig. 2 highlight that the carbohydrate fraction of EPS significantly affected the dewaterability during Phase II. In details sludge derived from aerobic and MBR reactors (Fig. 2c and d) resulted affected from carbohydrate in terms of CST as well as SRF. Conversely, in the anoxic reactor the influence exerted by the protein fraction resulted evident $(\mathrm{R} 2=0.81)$.

The anaerobic reactor resulted less affected by the EPS content likely due to the lowest TSS concentration.

\section{Conclusion}

The hardest sludge to be dewatered was found during the phases I, II and III. Such result points out the importance played by influent features in affecting dewaterability. Indeed, during the stepwise salinity increase, the CST as well as the SRF grew up. Moreover, when hydrocarbon was treated (Phase III), the dewatering operations resulted extremely difficult to accomplish. Moreover, this finding allows affirming that further study aimed at improving the dewaterability of sludge originated from industrial wastewater treatment are needed.

Acknowledgments. This research was funded by the Italian Ministry of Education, University and Research (MIUR) through the Research project of national interest PRIN2012 (D.M. 28 dicembre 2012 n. 957/Ric - Prot. 2012PTZAMC) entitled "Energy consumption and GreenHouse Gas (GHG) emissions in the wastewater treatment plants: a decision support system for planning and management" in which Giorgio Mannina is the Principal Investigator.

\section{References}

APHA (2005) Standard methods for the examination of water and wastewater. Stand Methods 541. doi:10.2105/AJPH.51.6.940-a

Bonilla S, Tran H, Allen DG (2015) Enhancing pulp and paper mill biosludge dewaterability using enzymes. Water Res 68:692-700. doi:10.1016/j.watres.2014.10.057

Capodici M, Di Bella G, Nicosia S, Torregrossa M (2014) Effect of chemical and biological surfactants on activated sludge of MBR system: microscopic analysis and foam test. Bioresour Technol 177. doi:10.1016/j.biortech.2014.11.064

Capodici M, Mannina G, Torregrossa M (2016) Waste activated sludge dewaterability: comparative evaluation of sludge derived from CAS and MBR systems. Desalin Water Treat 57. doi:10.1080/19443994.2016.1180478

Chen Z, Zhang W, Wang D, Ma T, Bai R, Yu D (2016) Enhancement of waste activated sludge dewaterability using calcium peroxide pre-oxidation and chemical re-flocculation. Water Res 103:170-181. doi:10.1016/j.watres.2016.07.018

Cosenza A, Di Bella G, Mannina G, Torregrossa M (2013) The role of EPS in fouling and foaming phenomena for a membrane bioreactor. Bioresour Technol 147:184-192. doi:10. 1016/j.biortech.2013.08.026

Ginestet P (2007) Comparative evaluation of sludge reduction routes. Eur Water Res Ser. doi:10. 1017/CBO9781107415324.004 
Jin B, Wilén BM, Lant P (2004) Impacts of morphological, physical and chemical properties of sludge flocs on dewaterability of activated sludge. Chem Eng J 98:115-126. doi:10.1016/j. cej.2003.05.002

Liu H, Xiao H, Fu B, Liu H (2016) Feasibility of sludge deep-dewatering with sawdust conditioning for incineration disposal without energy input. Chem Eng J 313:655-662. doi:10.1016/j.cej.2016.09.107

Low EW, Chase HA, Milner MG, Curtis TP (2000) Uncoupling of metabolism to reduce biomass production in the activated sludge process. Water Res 34:3204-3212. doi:10.1016/s00431354(99)00364-4

Marinetti M, Malpei F, Bonomo L (2009) Relevance of expression phase in dewatering of sludge with chamber filter presses. J Environ Eng ASCE 135(12):1380-1387

Mannina G, Capodici M, Cosenza A, Di Trapani D (2016a) Carbon and nutrient biological removal in a University of Cape Town membrane bioreactor: Analysis of a pilot plant operated under two different C/N ratios. Chem Eng J 296:289-299. doi:10.1016/j.cej.2016. 03.114

Mannina G, Capodici M, Cosenza A, Di Trapani D, Viviani G (2016b) Sequential batch membrane bio-reactor for wastewater treatment: the effect of increased salinity. Bioresour Technol 209:205-212. doi:10.1016/j.biortech.2016.02.122

Mannina G, Cosenza A, Di Trapani D, Capodici M, Viviani G (2016) Membrane bioreactors for treatment of saline wastewater contaminated by hydrocarbons (diesel fuel): an experimental pilot plant case study. Chem Eng J 291. doi:10.1016/j.cej.2016.01.107

Mowla D, Tran HN, Allen DG (2013) A review of the properties of biosludge and its relevance to enhanced dewatering processes. Biomass Bioenerg 58:365-378. doi:10.1016/j.biombioe. 2013.09.002

Rao B, Huang G, Lu X, Wan Y, Jiang Z, Chen D, Liu X, Liang A (2017) An ultrahigh-pressure filtration and device design and optimiz study on high dry dewatering of sludge. Process Saf Environ Prot 106:129-137. doi:10.1016/j.psep.2017.01.001

Skinner SJ, Studer LJ, Dixon DR, Hillis P, Rees CA, Wall RC, Cavalida RG, Usher SP, Stickland AD, Scales PJ (2015) Quantification of wastewater sludge dewatering. Water Res 82:2-13. doi:10.1016/j.watres.2015.04.045

Wang LF, He DQ, Tong ZH, Li WW, Yu HQ (2014) Characterization of dewatering process of activated sludge assisted by cationic surfactants. Biochem Eng J 91:174-178. doi:10.1016/j. bej.2014.08.008 